\title{
ПРЕДПЕРЕХОДНЫЕ ЯВЛЕНИЯ В ОБЛАСТИ СТРУКТУРНОГО ФАЗОВОГО ПЕРЕХОДА В КАРБОНАТЕ КАЛИЯ
}

\begin{abstract}
Методами спектроскопии комбинационного рассеяния исследованы процессы молекулярной релаксации в карбонате калия $\mathrm{K}_{2} \mathrm{CO}_{3}$. Установлено, что в кристаллическом карбонате $\mathrm{K}_{2} \mathrm{CO}_{3}$ структурный фазовый переход первого рода носит растянутый характер. Обнаружено существование предпереходной области в исследованном карбонате $\mathrm{K}_{2} \mathrm{CO}_{3}$. Дано теоретическое обоснование предпереходным явлениям на основе представлений о туннельных переходах.
\end{abstract}

Ключевые слова: комбинационное рассеяние, молекулярная спектроскопия, колебательная релаксация, ионные кристалль, предпереход, карбонаты.

\section{Введение}

Изучению структурных фазовых переходов в кристаллах, в том числе и в карбонатах, в последние годы уделяется большое внимание [1 -4]. Многие их них являются переходами первого рода. Известно, что в области фазового перехода первого рода «кристалл - расплав» имеют место явления предплавления [5]. Исследованы предпереходные явления в металлических сплавах [6, 7].

Можно предположить, что подобные предпереходные явления могут наблюдаться и при некоторых структурных фазовых переходах первого рода в кристаллах. Наряду с дифракционными методами, эти явления могут с успехом изучаться и спектроскопическими методами, чувствительными к локальным взаимодействиям и нарушениям в кристаллической решетке.

В работе [8] исследовались структурные фазовые переходы первого рода в кристаллах $\mathrm{KPb}_{2} \mathrm{Br}_{5},\left(\mathrm{NH}_{4}\right)_{2} \mathrm{WO}_{2} \mathrm{~F}_{4}, \mathrm{KPb}_{2} \mathrm{Cl}_{5},\left(\mathrm{NH}_{4}\right)_{2} \mathrm{NbOF}_{5}$. При повышении температуры разность показателей преломления сначала изменялась линейно и незначительно, а за 30-130 К до температуры фазового перехода наблюдается аномальное поведение двупреломления. Это особая температурная точка на температурных зависимостях. В этих кристаллах в широком интервале температур выше фазового перехода наблюдались сильные предпереходные явления, растянутые по температуре на 30 $70 \mathrm{~K}$.

Теоретические представления о предпереходных состояниях развиты в работе [9]. В последние годы они рассматривались в работах [10-19].

В качестве метода исследования структурных фазовых переходов в кристаллах удобен метод колебательной спектроскопии, в том числе и метод комбинационного рассеяния (КР) света [20]. В отличие от других методов в колебательной спектроскопии измеряются величины, характеризующие непосредственно отдельные молекулы или ионы изучаемой системы. Этими параметрами являются положение максимума (частота $v$ ) и ширина $w$ спектральной полосы. Малейшие изменения в микроскопической структуре и строении изучаемой системы, а также в динамике молекул и ионов отражаются на спектральных параметрах $(v, w)$ этой системы.

Поэтому исследование предпереходных явлений при структурных фазовых переходах первого рода в кристаллах методом КР может способствовать установлению характера изменения механизма ионной динамики при структурном фазовом превращении. При исследовании фазовых переходов типа «порядок - беспорядок» в нитратах щелочных металлов обнаружены предпереходные явления, изучение которых важно для понимания динамики процессов разупорядочения и ориентационного плавления в области растянутых фазовых переходов $[21,22]$. С точки зрения структуры рассматриваемых фаз некоторые превращения в твердом состоянии оказываются чрезвычайно важными для исследования и интерпретации процессов плавления.

В предыдущих работах мы исследовали область предплавления в кристаллах с многоатомными ионами методом колебательной спектроскопии $[23,24]$. При этом было установлено, что область предплавления наиболее четко проявляется в тех кристаллах, где выше симметрия молекулярного иона. В соответствии с этим, в настоящей работе в качестве объекта исследования был выбран карбонат калия $\mathrm{K}_{2} \mathrm{CO}_{3}$. Карбонат калия $\mathrm{K}_{2} \mathrm{CO}_{3}$ - это бесцветный кристалл моноклинной 
Уважаемые читатели!

Доступ к полнотекстовой версии журнала
«Известия высших учебных заведений. Физика» осуществляется на платформе Научной электронной библиотеки eLIBRARY.RU на платной основе:

https://elibrary.ru/contents.asp?titleid=7725 